CP, 2013 , N², pp. 41-53. ISSN 2014-6752. Girona (Catalunya). WICHELS, Susana: A MITIFICAÇÃO DA SEXUALIDADE NOS MÉDIA. Análise de Activa e Happy Woman.

Recibido: 27/02/2013 - Aceptado: 19/04/2013

\title{
A MITIFICAÇÃO DA SEXUALIDADE NOS MÉDIA Análise de Activa e Happy Woman
}

\author{
THE MYTH OF SEXUALITY IN THE MEDIA \\ Analysis of Activa and Happy Woman
}

Autora: WICHELS, Susana

\section{Mestranda em Comunicação e Jornalismo}

Faculdade de Letras, Universidade de Coimbra (Portugal)

susanaw@sapo.pt / www.susanawichels.com

\begin{abstract}
Resumo
Este artigo pretende verificar como o discurso das revistas femininas vincula a identidade da mulher portuguesa à beleza física e sensual, projeta uma imagem irreal do ideal de vida feminino e mitifica o papel da sexualidade.

O corpus selecionado para esta pesquisa, constitui-se por edições da revista Activa e Happy Woman, sendo o recorte temporal escolhido de Janeiro a Dezembro de 2012. Os magazines escolhidos constituem atualmente as revista femininas mais lida em Portugal, segundo dados recolhidos pelo estudo Bareme Imprensa do grupo Marktest.
\end{abstract}

\section{Palavras chave}

revistas femininas; estereótipos; sexualidade; mitos; género;

\begin{abstract}
This article analyses how the speech of woman magazines relate the identity of the Portuguese women to physical and sexual beauty, project an illusory ideal of feminine life and builds up the myth of sexuality.

The corpus selected for this research consists in editions from the magazine Activa and Happy Woman, published between January and December 2012. The selected magazines are the most read female magazines in Portugal, according to the study Bareme Imprensa from Marktest.
\end{abstract}

\section{Key words}

woman magazines; stereotypes; sexuality; myths; gender

\section{Introdução}

Partimos da ideia Barthesiana das narrativas como mitos, que contamos sobre nós e sobre o mundo social em que vivemos. Se mistificar significa criar um engano, a palavra mitificar está relacionada com a criação de um mito. Segundo Virgílio Ferreira (1992), um mito organiza não apenas a ordenação da vida a um fim, mas toda nossa estrutura moral, a nossa territorialidade, a nossa diferenciação social, as relações pessoais, a interiorização e exteriorização do nosso ser. «O mito positivo afirma e abre caminho, o negativo nega e abstém-se» (FERREIRA, 1992).

Barthes entendia o mito como um tipo de discurso conotativo, um modo de significação, uma metalinguagem. Segundo o seu ponto de vista semiótico, o 
mito apropria-se de um sigo de primeira ordem como significante e transforma-o através da apropriação num signo de segunda ordem. Os mitos funcionam como comentários simbólicos ou irónicos dos significados literais e oferecem-nos leituras alternativas imbuídas de sabor ideológico. Os textos mediáticos das revistas femininas operam como mitos, como lendas sociais com caráter explicativo de fenómenos naturais ou sociais não tendo necessariamente um fundo verdadeiro, nem factual, mas exprimem uma crença coletiva. Lévi-Strauss, no seu «Estudo Estrutural do Mito» (1977) situa o significado do mito entre a experiência e a crença, uma resposta cultural a estes dois paradigmas antagónicos. Entendemos neste artigo a mitificação da sexualidade feminina, como o fenómeno de representação das histórias da sexualidade feminina nos media. Através de reportagens, da escolha de imagens, da publicidade, os meios de comunicação, nomeadamente a imprensa escrita, as revistas femininas e neste caso concreto, as revistas Activa e Happy Woman contribuem para a representação mitificada da sexualidade da mulher portuguesa.

Partimos do pressuposto que o conceito de sexualidade varia segundo o padrão, a convenção de cada sociedade. A sexualidade não trata de questões meramente reprodutivas, está ligada de forma intrínseca ao nível psicológico do ser humano. Não se resume ao ato sexual, engloba todos os comportamentos, as preferências e predisposições relacionados com a sexualidade e é influenciada em cada época pelas normas sociais, institucionais e culturais: o que é considerado normal, é fruto de uma convenção. Michel Foucault na obra a "História da Sexualidade" (1984), refletiu sobre a sexualidade, as suas relações com a moral e o poder. Segundo o filósofo francês, a sociedade vitoriana, a igreja, a instituição "família", moralizou a sexualidade, que antes era vivida de uma forma mais livre. Os últimos dois séculos foram momentos de repressão sexual: o casal modelo reduziu a função sexual à reprodutora e a sociedade condenou, negou, expulsou tudo o que saía dessa norma. A hipocrisia social delegou a sexualidade anormal às clínicas psiquiátricas e aos clubes de prostituição. Pergunta Foucault: estaremos atualmente livres desses dois séculos de repressão sexual? A hipótese repressiva aponta que a restrição da sexualidade foi forçada pela revolução industrial, o homem necessitava centrar a sua energia na força produtiva e não dissipá-la em prazeres sexuais. Foucault faz tábua rasa deste paradigma e formula uma nova teoria sobre a sexualidade, segundo a qual esta não deve ser concebida como um dado da natureza que o poder tenta reprimir, mas como produto do encadeamento da estimulação dos corpos, da intensificação dos prazeres, da incitação ao discurso, da formação dos conhecimentos, do reforço dos controles e das resistências. A sexualidade é socialmente construída.

\section{Objetivos}

Muitos são os estudos, dissertações, teses feitas sobre a forma de representação da identidade da mulher, os estereótipos, a socialização do género, a ideologia e a sexualidade. O objetivo deste artigo é responder de forma singela, a algumas perguntas que encontrámos sem resposta no decurso das nossas investigações sobre o tema e entender a forma como as revistas femininas propõe a sexualidade às mulheres portuguesas. Partimos de um enquadramento teórico e passamos à análise das revistas Activa e Happy Woman, para responder às seguintes questões: Será a categoria de revistas femininas redutora ou necessária? Os mitos da feminilidade: resultado da construção cultural? O ideal de beleza da mulher de hoje é um colete-de-forças? Assistimos a uma crescente comercialização da sexualidade?

O enquadramento teórico escolhido para nortear esta pesquisa parte de autores de estudos feministas dos média: Betterton (1985), Wolf (1991), Lipovestski (2000), Silveirinha $(2001,2004,2008)$ e os artigos de Mota Ribeiro e Pinto Coelho (2005). Apresentamos também um enquadramento da representação segundo as perspetivas dos Estudos Culturais, Hall (2000, 2005) e uma abordagem crítica à sociedade de massas inspirada na Escola de Frankfurt, Adorno e Horkheimer (1944). No que concerne à definição de sexualidade, relação entre o discurso e o poder, partimos de Foucault $(1984,2004)$, para chegar à análise crítica do discurso de Fairclough (2001). 


\section{Metodología}

Escolhemos como caminho metodológico, a análise crítica do discurso, porque a consideramos idónea para a análise da influência das relações de poder sobre o conteúdo e a estrutura dos textos dos meios de comunicação e por estar tradicionalmente voltada para a crítica social, para o debate de questões ligadas à discriminação, género, à manipulação do poder, à construção de identidades. Esta área de investigação multi-disciplinar, articula numa lógica de complementaridade, as teorias linguísticas e uma teoria social influenciada pelo pensamento de Althusser, Habermas, Foucault, ou Bourdieu, entre outros.

Norman Fairclough, uma referência da teoria da análise crítica do discurso, tem centrado a sua investigação no papel da linguagem nas relações sociais e como agente integrador dos processos de mudança social. Entende a linguagem como um elemento da prática social, responsável pela criação, manutenção e transformação das significações. Para Fairclough (2001), os sistemas linguísticos são abertos à vida social, porque se constroem na interseção das macro funções da linguagem: a ideacional com a construção e a representação da experiência; a interpessoal com a construção e a representação das relações sociais e das identidades sociais; e a textual através do estabelecimento de elementos de ligação entre a prática discursiva e o texto. Encontramos em Fairclough a influencia das críticas desenvolvidas por Foucault. $\mathrm{Na}$ nossa sociedade, a maioria dos discursos dominantes são mediados pelos meios de comunicação, que os organizam e modificam de acordo com a sua lógica discursiva e características próprias. Em "A Ordem do Discurso", Foucault observa como os discursos que fluem na sociedade são controlados por formas de poder e de repressão. Entende o discurso como uma prática social resultante de relações de poder, conjunto de enunciados apoiados numa mesma formação discursiva e que depende do equilíbrio de forças que se modificam de acordo com o contexto e a época em que estão inseridos.

Foucault propõe que pensemos e interpretemos o discurso a partir das condições e relações históricas e concretas que permitiram o seu aparecimento. Para realizar uma construção discursiva do social, para analisar o discurso dos média, concretamente das revistas Activa e Happy Woman, segundo Foucault (2004), devemos recusar as explicações unívocas e as fáceis interpretações, e por outro lado, não procurar insistentemente o sentido último ou oculto das coisas.

Outro pressuposto de que partimos é que atualmente, o processo de socialização e de construção de identidades sociais, subestima as referências coletivas tradicionais e passa a identificar-se cada vez mais nos meios de comunicação. Assistimos à perda de poder das antigas instituições de controlo social ou de referência coletiva como a família, a igreja, o casamento, a escola, que não contribuem como outrora para a construção de identidades sociais. Estes são o locus de informação, educação e controlo dos públicos. Segundo Horkheimer e Adorno (1944) a indústria cultural fez dos meios de comunicação um meio de controlo psicológico espantoso. É a indústria do conformismo e do formalismo pois oferece indicações precisas acerca do que se deve e do que se não deve fazer. Uma das estratégias de domínio é a definição da cultura dos estereótipos, crenças socialmente compartilhadas, que promovem a homogeneidade grupal. Os estereótipos são um elemento fulcral para organizar e antecipar as experiências da realidade social, já que ordenam o caos cognitivo, a desorganização mental e fornecem padrões de conduta que condicionam o mundo real, das mulheres, dos comportamentos de consumo, dos comportamentos psicológicos, dos desejos e dos sonhos femininos.

Por outro lado completámos o método de análise qualitativa com um modelo de análise quantitativo. Partindo de Quivy e Van Campenhoudt (1992:140) utilizámos o modelo de análise para estabelecer um sistema de relações e manter um padrão lógico entre os elementos constituintes. Assim articulámos as proposições hipóteses que pretendemos testar (Silverman 2006:52) utilizando conceitos operatórios isolados, isto é empíricos, através da observação direta e de informação recolhida (Ferin, 2012:68). Contabilizámos as páginas de publicidade versus páginas editoriais, tipologia de artigos em capa atendendo especialmente aos que se relacionavam com sexo, número de chamadas em capa e relação com o desenvolvimento dos artigos, número de vezes que se utilizam termos relacionados com a sexualidade, pre- 
domínio de artigos relacionados com o sexo em relação a outros temas, como o económico, doméstico, cultural, moda, político, família ou outro e avaliação da presença de conteúdo sexual em publicidade.

Partiremos agora para a apresentação das revistas, dos dados resultantes da análise quantitativa. Passaremos depois à análise do conteúdo das reportagens, imagens e publicidade do corpus elegido, a fim de recolher dados que nos permitam responder às perguntas que norteiam esta pesquisa.

\section{Análise do Corpus}

Começaremos pela apresentação da Activa e Happy Woman, as revistas femininas portuguesas com maior circulação e conteúdos femininos genéricos, similares aos magazines internacionais de referência. As revistas femininas mensais de estilo de vida foram lancadas em Portugal no pós-25 de Abril, primeiro com a Maxima em 1988, a Cosmopolitan em 1992, a Activa em 1993 e a Happy Woman, mais tarde, em 2006.

A Activa teve uma tiragem media em 2012 em de 78069 (dados da Associação Portuguesa Control de Tiragens), cada edição uma média de 172 páginas, tem um preço de capa de 2,90 Euros e divide-se em várias seç̧ões: $\mathrm{Na}$ Capa, Corpo, Moda, Arte de Viver, Crianças e Adolescentes, Casa. Outras secções nem sempre presentes são: Dinheiro e Trabalho, Natal. Em todas as edições encontramos uma forte componente publicitária, sendo inúmeras as paginas inteiras de publicidade que intercalam as páginas de artigos. Nas 12 edições analisadas, encontramos um 37\% do espaço dedicado à publicidade, contabilizando só os anúncios de página inteiras e páginas duplas. Encontrámos que 7\% dos anúncios estão relacionados com crianças, mas a maioria está dedicada a cosmética (37\%); moda e acessórios (30\%) e os restantes a outros produtos de consumo.

Em 2012 a revista Happy Woman teve uma circulação media de 170253 (dados APCT) e desde seu primeiro número em 2006 que usou a sexualidade como a primeira arma de venda. A sexualidade está patente, seja no conteúdo visual da revista, nos seus artigos e na publicidade. Contém também uma grande componente relacionada com a moda, acessórios e produtos de beleza e tendências sazonais e escassa utilização de celebridades, separando-a assim claramente da denominada imprensa cor-de-rosa. A capa é protagonizada por uma modelo "anónima" ao contrário da revista Activa onde sempre aparece uma modelo ou atriz conhecida. A média de páginas por edição é de 178 e tem um preço de capa de 2,50 euros. A estrutura da revista está composta por seç̧ões $\mathrm{Na}$ Capa, Editorial, Clube Happy - onde oferecem descontos em produtos e serviços orientados a um estilo de vida centrado no consumo e nos prazeres do corpo. Outras secções são o Shopping bag, Happy end, Saio, Decoro, Leio, Navego, Testo, Uso, Anoto, Sigo. São espaços rubrica onde se mostram imagens e acessórios, comparação de marcas e produtos, sugestões de viagens e escapadas de fins de semana, visitas a spas ou a outros locais de tratamentos para o corpo. Nas 12 edições analisadas, encontramos um 39\% do espaço dedicado à publicidade, contabilizando anúncios de página inteira e páginas dupla. Constatámos que em 10\% dos anúncios havia o uso explicito do nu e da sexualidade. Os anúncios são na sua maioria dedicados a produtos de cosmética, moda e acessórios, com ausência de anunciantes de produtos para famílias ou crianças.

Encontramos nos titulares da capa da revista Happy Woman a seguinte predominância de temáticas: sexualidade, a astrologia ou a felicidade. Existe na revista um tónico geral orientado ao estilo de vida hedonista, egocêntrico, o bem-estar individual e o usufruto de todos os prazeres, com especial ênfase ao sexo. Pela linguagem e enfoques escolhido, o preço de capa e os looks de moda sugeridos, podemos concluir que a Happy Woman orienta-se a mulheres jovens e solteiras entre os 20 e os 35 anos, sendo que a revista Activa, está orientada para mulheres entre os 25 anos e os 45 anos, com uma relação estável ou com projetos nesse sentido e que dão valor ao estilo de vida familiar, ao casamento e à maternidade. 
Embora exista esta diferenciação etária, em ambas revistas encontramos que as secções projetam o ideal da mulher portuguesa atual: independente económica e financeiramente, com uma carreira profissional de êxito, cara, corpo e look perfeitos, com família, crianças e marido (no caso da Activa) e solteira com relações livres (no caso da Happy Woman). As reportagens, os textos publicitários, as fotos representam as mulheres de uma determinada forma, constroem estilos mediante a escolha de posturas do corpo, de roupas e acessórios. Encontramos uma forte componente visual e uma forte relação entre texto e imagem: o uso da cor para estabelecer conexões entre colunas com a mesma temática e outros detalhes visuais que constroem a identidade de imagem genérica da revista.

O discurso narrativo está fortemente baseado na imagem e a paginação é feita de forma a apelar ao sentido visual. Não encontramos em nenhuma das 12 edições analisadas de ambas revistas, nem uma página composta só por texto: existe sempre e pelo menos, uma pequena imagem, seguida de uma página completa de anúncios. O sentido olfativo é também estimulado, porque há páginas com promoções de perfume e o sentido do tato, quando existem páginas duplas e obriga-nos de forma lúdica a desdobrar a revista para descobrir o conteúdo do anúncio publicitário.

Segundo Helen Fulton (2005:280) as narrativas oferecidas pelos magazines femininas são compostas por linguagem e imagem e cabe ao leitor decidir sobre as possíveis relações entre elas. Desta forma, antes de começar a ler o texto, somos impactados pela imagem, que nos orienta sobre quais as expectativas a ter em relação à notícia. Quando lemos a linguagem textual, encontramos geralmente a confirmação dessas expectativas. Porque o produto mediático oferecido por estes magazines é composto pela simbiose indissociável de linguagem textual - imagem é apropriado fazer uma análise detalhada de ambos e das suas possíveis relações. Os componentes verbais como títulos, subtítulos, ou textos escritos, articulam-se com as imagens e fotos, numa lógica semiótica que garante uma coerência semântico-pragmática. Os textos e as imagens perfazem um todo coerente. Além dos aspetos semióticos, acreditamos ser interessante refletir refletir sobre algumas escolhas lexicais. Encontrámos com frequência o uso das palavras "Sexy" e "Sensual", seja em relação a peças de roupa, acessórios, comportamentos, pessoas. $\mathrm{Na}$ revista Happy Woman encontramos uso más acentuado de títulos e palavras em língua inglesa (a começar pelo próprio título da revista) enquanto que na Activa são um pouco mais comedidos no uso de estrangeirismos. Cremos que o uso de palavras inglesas na Happy Woman relaciona-se com o facto de estar direcionada a um público alvo mais jovem e mais sensível à globalização.

Em relação à quantidade de títulos de artigos patentes nas capas, encontrámos no corpus analisado uma média de 11 chamadas na Happy Woman, em quanto que na Activa o número é bastante menor, 6 chamadas de capa. Pode-se explicar esta diferença porque na Activa os artigos são mais longos e o tratamento do material jornalístico é feito com maior profundidade, sendo que na $\mathrm{H}$. W. utilizam fórmulas jornalísticas mais curtas e mais superficiais.

Passaremos agora a uma análise crítica do discurso de algumas peças textuais. Devido ao constrangimento de espaço do presente artigo, escolhemos três exemplos representativos: um anúncio publicitário, uma sessão fotográfica de moda, e uma reportagem tipo "caça-homens". O critério para esta seleção foi a relevância dos textos e imagens para as questões da pesquisa apresentadas na introdução.

\subsection{Análise de um Anuncio Publicitário - “Joias de Eugénio Campos by Diana Pereira”}

O anúncio é composto por uma página completa ímpar da revista, a zona com maior visibilidade e com maior valor comercial. O anúncio foi colocado

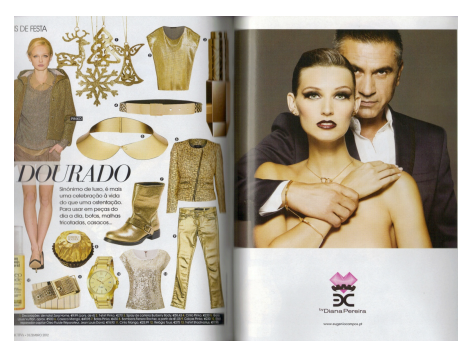
de forma estratégica ao lado de um fotorreportagem de acessórios de moda relativos ao Natal, cujo denominador comum é o tom dourado. À primeira vista, a leitora distraída tratará de pensar que as duas páginas compõem o mesmo anúncio, já que existe 
uma coerência na paginação, na cor e distribuição dos elementos.

Ao prestar mais atenção, a leitora distinguirá que são coisas diferentes: a página da esquerda apresenta sugestões de acessórios escolhidos pelo departamento de moda onde se sugere à leitora que o que está na moda são os acessórios dourados, enquanto a página da direita é a publicidade de jóias douradas da marca Eugénio Campos.

No anúncio aparece um plano médio de uma mulher loura, magra, adulta, muito maquilhada e nua mas não expõe os seus seios. Tem-nos habilmente escondidos pelo braço direito e também pelo corte da fotografia. Mas cobrir os seios não é a função desse braço teatralmente disposto na diagonal, fixamo-nos nele ao procurar o seio escondido, mas o que encontramos é uma jóia, uma pulseira de ouro que ata a mulher ao pulso da segunda personagem do anúncio: um homem adulto, na casa dos 45 anos, vestido impecavelmente, com um fato e camisa branca indicadores de poder económico-, tez morena indicador de que tem tempo para ir de férias, viajar a sítios tropicais ou jogar ao golf-, cabelo grisalho indicador de maturidade e poder. O homem, que os publicitários classificariam de "best age" aparece numa pose de dominação pura. O seu olhar desafiante, de baixo para cima, é quase animalesco. $\mathrm{O}$ homem tem a mulher indefesa e nua, maquilhada como uma boneca e com ar apático, atada, presa, dominada, um corpo dócil.

Esta modelo-nua-boneca-dominada não é anónima. A mulher portuguesa leitora da Activa provavelmente reconhecerá a modelo, trata-se de Diana Pereira, uma pseudo-celebridade na sociedade portuguesa, modelo que ganhou há alguns anos um concurso de new models e que desde então tem singrado no mundo da moda nacional. Se ninguém a identificasse (já que o rosto aparece excessivamente maquilhado em contraste com a pele nua do corpo), a fotografia do anúncio é acompanhada pelas palavras "Eugénio Campos by Diana Pereira".

As jóias parecem ser assinadas ou criadas pela própria modelo e por isso, a marca Eugénio Campos (homem) são assinadas (by) Diana Pereira (mulher). O layout distribui os elementos semióticos do anúncio: a foto ocupa dois terços da página e a divisão inferior sugere a divisão ideal / real; a marca ocupa ocupa a posição central. Como vimos anteriormente, devemos considerar em conjunto as palavras e imagens, e que sejam analisadas como signos. Isso significa dizer que elas são 'formas físicas' (significantes) com significados. A foto restringe as escolhas possíveis dos diversos significados. Há uma ligação entre a postura da modelo e a proposta do anúncio que apresenta, aparentemente, um discurso inovador acerca das identidades femininas. Os atributos físicos da modelo (magra e nua) situam-na no discurso estético da pós-modernidade. Este anúncio faz saltar os alarmes em qualquer estudo sobre representação de género, de violência, de domínio sexual. O feminino é representado de forma frágil (nua e atada) e fútil (maquilhada em excesso e sem expressão no rosto).

\subsection{Análise de uma sessão fotográfica de moda}

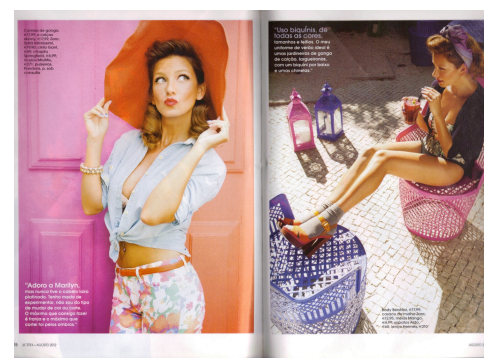

Esta sessão fotográfica é composta por seis páginas de fotografias, onde uma modelo-atriz adota posturas de estilo pin-up. Por constrangimento de espaço, vamos centrar a nossa análise na primeira página. O propósito desta reportagem fotográfica é trazer às leitoras alguns exemplos de moda para o verão e ao mesmo tempo conhecer alguns diques de estilo da pseudo conhecida atriz.

Um dos aspetos semióticos a observar é o uso de cores fortes o que produz uma impressão sensorial envolvente, os laranjas, os azuis, a luz intensa, lembram o verão, os gelados de sabores tropicais, os lolipops.

A atriz aparece maquilhada e com roupas sexy, adotando posturas corporais de estética pin-up. Recordemos que pin-up, aparte de significar poster para afixar na parede, tem outro significado em Inglês, significa cheesecake, neste sentido denominase a rapariga bonita que está melhor que um queijo: "it's better than a cheesecake". Desde os anos 50, até hoje, este ideal de beleza sensual, modalizou um padrão de comportamento, um mito de libertação 
sexual feminino. A sessão fotográfica é muito heterogénea em relação aos géneros discursivos. Ao lado das fotos, dois pequenos textos, um com informações publicitárias, os preços e marcas das roupas e acessórios usados pela modelo e outro texto intitulado «Adoro Marylin» uma espécie de depoimento da modelo sobre o seu conceito de ideal de moda e beleza. A sessão fotográfica contribui para a construção das identidades sociais das leitoras através da linguagem imagética e textual, neste caso, por meio da linguagem usada para a formação das identidades de género. Aqui claramente, encontramos representada uma imagem de mulher-boneca-sensual. Mas esta sessão fotográfica é também composta pelos depoimentos de estilo da atriz. No texto «Adoro Marylin, mas nunca tive o cabelo loiro platinado. Tenho medo de experimentar, não sou do tipo de mudar de cor ou corte. O máximo que consigo fazer é franja e o máximo que cortei foi pelos ombros», a modelo diz que o seu ideal de beleza é Marylin Monroe, a pinup loira e sensual, no entanto confessa não ser capaz de imitar o seu ideal porque tem "medo de experimentar". É interessante observar a dicotomia entre o que a modelo diz e o que faz: no texto diz-nos: "o máximo que consigo fazer é franja e o máximo que cortei foi pelos ombros" -notar que a palavra máximo aparece duas vezes numa oração tão curta-. No editorial de moda a modelo faz o contrário do que acaba de dizer e aparece penteada com vários estilos sexy, maquilhada, vestida e em posturas pinup ao estilo Marylin. A mulher que está por detrás da produção de moda declara insegurança em ser loira platina na realidade, isto é, em assumir o seu ideal de beleza e sexualidade, no entanto, aceita produzir-se e disfarçar-se de pin-up para a produção de moda. A modelo encarna o ideal de beleza na sessão fotográfica e declara no texto que esse é o seu ideal "ADORO Marylin", mas na sua vida real assume outros padrões de comportamento, onde estabelece um máximo do que se lhe é permitido fazer ou ser. Esta contradição entre o que diz e o que faz, entre o que idealiza e o que pretende ser, pode ser extrapolada para a análise geral do próprio discurso das revistas femininas como explicaremos mais adiante.

\subsection{Análise de um artigo de tipo "guia caça- homens"}

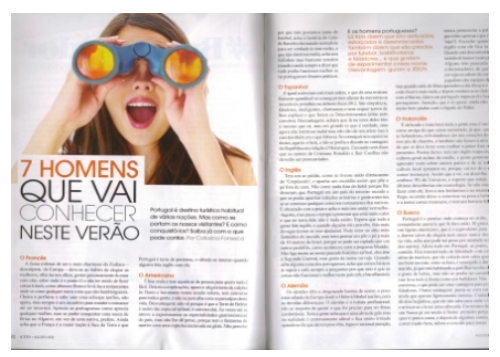

Outra

especialidades das revistas femininas é o artigo "caçahomens", uma espécie de manual de ajuda sobre sexualidade e relações afetivas. As revistas portuguesas têm vindo a publicar este tipo de artigo desde a década de 80 , altura em que na nossa sociedade, a mulher independente começou a tomar as rédeas da sua vida, da sua carreira, do seu trabalho e da sua sexualidade. A mulher já não é passiva na conquista, como aprendeu a tomar a iniciativa. Este tipo de mudança social é especialmente importante para a sociedade portuguesa, marcadamente católica e com restrições sexuais e comportamentais. Este tipo de artigo teve e tem um papel pedagógico ao ensinar a mulher a viver a sua sexualidade, livre de tabus e imposições sociais.

O artigo sobre os "7 Homens que Vai conhecer neste Verão" é composto por duas páginas, uma imagem e por texto dividido em parágrafos, um por cada nacionalidade de homem que supostamente a leitora terá a possibilidade de conhecer. A fotografia escolhida para ilustrar o artigo é de uma mulher com grandes binóculos e a boca aberta, feliz, receptiva, maquilhada, pronta para a caça dos espécimes masculinos. Pensemos no tom positivo do artigo, começando pelo título: "7 Homens que Vai conhecer neste Verão". A escolha do verbo e do tempo presente "Vai" indica claramente à leitora que ela terá com certeza, êxito neste Verão. Não se escolheu a fórmula "poderá conhecer neste Verão" mas sim "Vai conhecer neste Verão". Com otimismo, o artigo enumera uma quantidade possível de parceiros: 7 homens. Esta mensagem liberta a mulher portuguesa, condicionada culturalmente a ser recatada, e convida-a a extrapolar fronteiras dentro do seu país, que é aceitável conhecer vários homens portugueses ou estrangeiros. O artigo passa depois a caraterizar os diferentes tipos de homem segundo a sua nacionalidade, tendo por objetivo preparar mentalmente a mulher com informação que a ajude no campo de caça. $\mathrm{O}$ conteúdo do 
artigo é superficial, caindo uma vez mais nos arquétipos e nos mitos, criando uma caricatura masculina bastante redutora. Mas o que está aqui em causa não é fornecer informação fidedigna sobre o espécime francês, alemão ou sueco, mas sim dotar a mulher de auto confiança "saiba já com o que pode contar”, prepará-la mentalmente para adotar uma postura livre e usufruir de relações afetivas e sexuais mais livres e menos condicionadas culturalmente. Usando o exagero, a caricatura, este artigo apre- senta um discurso libertador e emancipatório da sexualidade feminina.

Segundo David Gauntlett (2002), este tipo de artigos comuns a várias revistas femininas sugerem que um homem é o caminho de felicidade e de alguma forma estão a reproduzir uma versão mais elaborada da antiga ideia de que se as mulheres conseguirem ser suficientemente bonitas e perfumadas, serão contempladas com a sorte de um homem vir tirá-las da realidade, de preferência em felicidade conjugal.

\section{Problematização e Sistematização}

Passamos a agora abordar as questões levantadas na introdução desta pesquisa.

A Marktest, no seu estudo de hábitos de audiência de imprensa -Bareme de Imprensa- classifica as revistas segundo as várias categorias, e entre elas encontramos a categoria de revistas Femininas, que inclui os títulos: Certa, Lux Woman, Activa, Ana, Cosmopolitan, Elle, Happy Woman, Maria, Máxima, Mulher Moderna, Ragazza, Telenovelas. Uma classificação similar existe em todo o mundo e tem raízes históricas. No entanto importa perguntar se nos dias de hoje, faz ainda sentido este tipo de categorizações e se a categoria "revistas femininas" é redutora ou necessária. Estaremos assistindo ainda a um resquício discriminatório e redutor do universo feminino? Acaso as mulheres não se interessam por política, economia, historia ou desporto? Talvez a explicação resida na própria história da imprensa feminina. Existem registos históricos de que a imprensa feminina surgiu em meados do século XVII, em França com a Gazette de France (1631) ou em Inglaterra, a Ladies Mercury (1693). No século XVIII, continuaram-se a produzir vários jornais realizados por e para mulheres. Tinham em comum uma função pedagógica que ensinava a mulher a ser e a comportar-se segundo o padrão aprovado na época. Foi no século XIX, que apareceram as primeiras revistas femininas, mais parecidas com o género atual e com conteúdos que variavam entre a educação das mulheres e outros mais emancipatórios. Recordemos que a evolução das revistas femininas está intimamente ligada com a evolução histórica do papel da mulher na sociedade. As revistas ilustradas como as conhecemos hoje, chegaram na década de 30, sendo a publicação Life (1936) um marco no caminho das revistas femininas: não só porque as fotografias revolucionaram a estrutura narrativa, mas também os conteúdos começaram a estar orientados ao consumo, alterando o enfoque dos temas considerados de forma tradicional como femininos: a casa, a família, a decoração, a moda.

Tal como Helen Fulton em Narrative and Media, reportámo-nos à origem etimológica da palavra magazine, que significa em árabe “armazém” para fazer uma extensão semântica linear: um magazine é um armazém de artigos, uma coleção de elementos selecionados. Os magazines femininos são pequenos armazéns do universo feminino. No entanto, folheando a revista Activa e a Happy Woman navegando entre as suas secções, ficamos com a sensação de que a mulher retratada não é real, mas sim uma pseudomulher que articula trabalho, família, moda, sexo, culinária e decoração, tudo isso sem desequilibrar-se dos seus saltos agulha de $15 \mathrm{~cm}$ e com o cabelo e a maquilhagem perfeitamente em ordem. A Activa e Happy Woman, não diferem muito das revistas de mainstream que encontramos nos aeroportos espanhóis, asiáticos ou americanos. Poderia chamarse Vogue, Elle, Marie Claire, Cosmopolitan, já que contém o mesmo mix and match de conteúdo, os mesmos anúncios, os mesmos modelos, os mesmos cosméticos, os mesmos perfumes. A globalização chegou à publicidade e os anunciantes compram em bulk às grandes centrais de compras, espaços nas revistas de todo o mundo. As campanhas das grandes marcas, Esteé Lauder, L'oreal, Gucci, usam a mesma imagem publicitária na revista feminina portuguesa, espanhola, francesa ou japonesa. As embaixadoras 
dos sonhos, modelos perfeitas, atrizes ou desportistas de sucesso, são eternizadas pelas lentes dos grandes fotógrafos, produzidas e maquilhadas até atingir a perfeição e se ainda ficar algo imperfeito, será imediatamente disfarçado com algum software de correção fotográfico. Tudo isto para vender os mesmos produtos a escala mundial, para que milhares de meninas, raparigas, mulheres desejem o mesmo, comprem o mesmo e sonhem o mesmo.

Mas as revistas femininas têm também uma função social, são manuais de auto-ajuda, substituem os conselhos das amigas e são utilizadas pelas mulheres de todo o mundo como guias de comportamento nas diferentes áreas da vida: "O que vestir para uma reunião de trabalho» "Educar o seu bebé a deixar de usar o bacio» "Como maquilhar-se para uma noite de festa». As revistas conformam esse espaço onde a coesão feminina é possível, oferecem o conselho sábio, são a irmã mais velha, a mãe, a amiga, a confidente, de muitas leitoras. A voz das revistas femininas, estimula e constrói uma aliança de confiança com a leitora, está disponível ao seu lado, com conhecimentos, recursos, serviços e respostas que a maioria das mulheres não seria capaz de perguntar entre pares.

A beleza e a sexualidade são os temas dominantes dos conteúdos deste género mediático, e no entanto as revistas femininas têm um enorme potencial como agentes de mudanças sociais. Apesar do seu conteúdo aparentemente banal as revistas assumem um importante papel no mundo feminino: a cultura de massas orientada para o seu género.

As revistas femininas são um produto específico escrito e pensado para e por mulheres e que levam a sério as preocupações femininas e versando temas de interesse femininos. Talvez seja a falta de conteúdos específicos para o público feminino que as torna tão populares. Já que a cultura de massas adota tradicionalmente um ponto de vista masculino sobre o que é ou não notícia. A cultura de interesse geral, é dominada pelo pensamento masculino e ainda existe uma representação minoritária das mulheres. Em 2005, as investigadoras Mota-Ribeiro e PintoCoelho, realizaram um estudo sobre as Imagens de mulheres na imprensa portuguesa e chegaram à conclusão que existe uma sub-representação das mulheres: de 271 imagens analisadas num dia específico na imprensa geral, só 41 incluíam mulheres. E os jornais tradicionais ainda relegam as questões sobre o mundo feminino para as páginas femininas.
Da análise do corpus identificámos que as revistas femininas, apresentam um discurso ambivalente, ora pró-feminista, ora pró-barbie, refletindo as contradições próprias da mulher, que embora busca a emancipação, não deixa de estar controlada por um mundo e uma cultura dominante masculina, de poder e de dinheiro. "As revistas refletem a trégua incómoda pela qual as mulheres pagam o poder e a liberdade de ação através da preocupação com a beleza.» (WOLF, 1991:78)

Mas, se a maioria das jornalistas das revistas femininas são mulheres, porquê $70 \%$ dos conteúdos continuam a ser sobre temas banais? As revistas dependem da publicidade para sobreviver, precisam de financiar os conteúdos "sérios", onde se revelam as preocupações femininas, os assuntos interessantes e específicos para mulher e combinar estas mensagens, com as mensagens de superficialidade da beleza patrocinadas pelos anunciantes. A personalidade da revista, a sua consciência editorial, as motivações das jornalistas e as mentes das suas leitoras, dividem-se "entre o mito da beleza e o feminismo, exatamente com a mente das suas leitoras"(WOLF, 1991:78)

Assim, embora apontemos o excesso de superficialidade aos conteúdos das revistas femininas, devemos também reconhecer que têm acompanhado e difundido ao longo dos anos, as ideias de feminismo e de emancipação da mulher, como nenhum outro meio de comunicação. É através delas que as mulheres conhecem os seus direitos, tomam contacto com exemplos de outras mulheres, outras vidas, de outras vivências. São manuais de ajuda, dão voz à luta contra a violência de género, contra $o$ estupro, abordam as questões do aborto, empreendem uma luta feroz contra a discriminação de género, de defesa dos direitos humanos, de ajuda à vítima. E se por cada página de jornalismo feminino sério, é preciso aguentar quatro de publicidade a cosméticos e cirurgia estética, pois que assim seja, porque ainda que banais e superficiais, as revistas femininas são o que de mais genuíno possuem as mulheres na sociedade de informação.

Se por um lado, aí se constrói o mito da beleza e da sexualidade, também é aí que encontramos críticas mordazes e inteligentes a este mesmo sistema. Uma espécie de mensagem codificada e estratificada que exige às leitoras, especialmente às mais informadas, a capacidade de reter o que é importante (o jornalismo sério e especializado) e obviar os anúncios e as 
publirreportagens sobre futilidades e que existem como patrocínio dos conteúdos "sérios".

Constatamos que a Activa, mais do que a Happy Woman não é só um recipiente de artigos de beleza e cosmética. Nos 30\% restantes encontramos jornalismo dedicado a temas mais sérios, ficções escritas por e sobre mulheres, reportagens com mulheres de sucesso e espaço dedicado ao debate de legislação ou temas políticos do interesse feminino. Assim, mesmo que este espaço de reflexão do universo e preocupações legitimamente femininas, esteja escondido entre anúncios de cremes para olheiras e perfumes, não deixa de ter uma enorme importância emancipatória.

Não existe em Portugal nenhum jornal de interesse geral que trate os temas femininos com a seriedade necessária e com a mesma importância que costumam dar aos temas de interesse masculino. Concluímos pois que a categoria de revistas femininas é necessária porque embora possam ser classificadas como superficiais e fúteis, este tipo de imprensa especializada tem tido e continuará a ter, seja em formato papel ou digital, um papel fundamental na construção e representação do universo feminino.

"Não satanizemos os média femininos - há que interpretar a sua ação, simultaneamente, como um meio de orientação coletiva dos gostos e como um vetor de personalização e de auto-apropriação estética.» (Lipovetsky, 2000:165)

Dada a evolução do papel da mulher na sociedade e a uma progressiva conquista dos direitos de igualdade de género, caíram vários mitos e imagens de estereótipos femininos criados pela sociedade masculina. As mulheres entraram em massa no mundo do trabalho, conquistaram autonomia e independência financeira e igualdade em relação aos homens, beneficiaram-se do aparecimento do métodos contraceptivos e de antibióticos para usufruir de uma sexualidade não vinculada à reprodução e sem medo de doenças sexualmente transmissíveis. No entanto, talvez em resposta ao crescente poder feminino, o poder dominante, encarregou-se de reforçar o último dos mitos: a beleza e a sexualidade feminina. Os últimos mitos da feminilidade são resultado da construção cultural e do poder hegemónico presente na sociedade.

Esta reação não é conspiratória, mas resultado da soma de milhões de reflexos e reações individuais, de opiniões formadas, de pequenas segregações nas empresas, nas famílias, e que se fundem numa atmosfera impalpável que tende a oprimir as mulheres. Este movimento disperso e difuso é ainda mais perigoso porque está de tal forma disseminado que se torna difícil identificá-lo e apaziguá-lo.

Esta questão é especialmente importante porque as vozes que se levantam contra o feminismo não são só masculinas, mas também femininas. Mulheres condicionadas culturalmente a aceitar o seu papel baseado no discurso dominante masculino, ou mulheres que negam a existência do problema, porque se sentem pressionadas e censuradas pela linha invisível do poder das instituições masculinas, ou por mulheres que aproveitam de forma descarada e imoral o jogo sexual e tiram partido pessoal dele. E essa minoria desacredita a luta pela justiça social feita pela grande maioria.

Olhando a história da humanidade, nunca como hoje, os papéis sexuais foram postos em causa. Muitas mulheres sentem sentimentos de incerteza e culpa em relação ao seu papel na vida pública e profissional, e muitos homens sentem-se inseguros em relação ao seu próprio papel, medo em relação à expetativa de fortalecimento do poder feminino nas empresas, política e sociedade.

$\mathrm{Na}$ Activa e na Happy Woman, bem como nas revistas femininas de todo o mundo, Vogue, Elle, Cosmopolitan, a sexualidade, associada ao amor, é um ingrediente fundamental e importante para a fórmula da felicidade feminina contemporânea. E o êxito da sexualidade está diretamente relacionado com o ideal de beleza vigente, um corpo e rosto jovens e perfeitos, ou o que Wolf chama o «O Mito da Beleza». A fórmula da felicidade feminina que as revistas parecem transmitir resume-se à mitificação da sexualidade, dependendo do corpo que as mulheres forem capazes de ter. O discurso das revistas femininas promove uma cultura consumista, com as suas reportagens, imagens, publicidades, constrói discursivamente estilos de ser e representações identitárias.

As revistas celebram uma tendência que vincula a felicidade à beleza e à vida afetiva e sexual compensatória. Numa cultura que valoriza o bem-estar individual vinculado à sexualidade, ter uma vida sexual ou uma aparência que não corresponda as imagens publicadas nas revistas femininas, ao estereótipo celebrado é motivo de angústia, tristeza, ansiedade e depressão. Enquanto a modelo magra, alta, perfeita e o imperativo do sexo e da beleza sensual inundam as 
páginas das revistas e dos sonhos femininos, milhares de mulheres sentem-se inferiorizadas e com baixa auto estima. Segundo Stuart Hall (2000) a identidade constrói-se cronologicamente através de processos inconscientes, não provém de algo inato no momento do nascimento. A construção da identidade atravessa atualmente um momento instável, na sociedade capitalista surgem novos valores a todo o momento e existe uma tendência ao egoísmo, aos interesses individuais. As construções de identidades sociais, culturais, profissionais, religiosas e sexuais, estão hoje em constante formação e mudança, tal como os processos de representação, e a forma que imaginamos ser vistos pelos outros. Existe uma identificação inconsciente ou imaginária, ao procurar na imagem do modelo, o eu ideal.

Verificamos nas edições da revista Activa e da Happy Woman a utilização da relação de poder exercida sobre a mulher: aquela que não tem o corpo, a cara, uma carreira profissional brilhante, uma relação afetiva e sexual excitante, torna-se parte das excluídas da sociedade, parte da subclasse.

Foucault observa a génese de uma identidade, associada à sexualidade e a fixação do indivíduo a ela como efeitos do poder normalizador, que impediria o homem de constituir-se livremente a partir das suas particularidades. Na História da Sexualidade observa como os meios de comunicação incorporam no seu discurso as práticas sexuais. Embora elas existam desde sempre na história da humanidade, foram os meios de comunicação que fizeram com que entrassem no esquema de produção em série e de circulação em massa. A sexualidade entrou na vida de milhares de mulheres, a partir do século $\mathrm{XX}$, não controlada pelo discurso moral e castrador da Igreja, família ou casamento, mas sim através das páginas gloss das revistas femininas. Os meios de comunicação perceberem o interesse e a procura do público por este tipo de conteúdos e fizeram com que a sexualidade entrasse na lógica das indústrias culturais, e as indústrias dos cosméticos do culto ao corpo, iniciaram a comercialização da sexualidade.

Será então, que a sexualidade faz parte fulcral da identidade do indivíduo? A mesma pergunta foi formulada por Gauntlett, à qual respondeu com uma completa certeza: nos dias de hoje, através dos discursos das revistas femininas, dos livros de autoajuda e de toda a parafernália dos diferentes formatos mediáticos massificados, reforça-se a ideia de que a sexualidade é essencial para felicidade do indivíduo. Gauntlett (2002:123), enuncia a fórmula da felicidade proposta pelos meios de comunicação atuais: uentende a tua própria sexualidade + tem sexo frequentemente + procura ajuda para resolver problemas sexuais + tem um parceiro sexual satisfatório (ou encontra um novo).»

O corpo feminino hoje, é objeto de explorações comerciais, cientificas, industriais. A beleza que antes estava associada à saúde, ao bem-estar emocional e físico, hoje depende do esforço que a mulher esta disposta a realizar, à quantidade de procedimentos cosméticos, estéticos a que está disposta a submeter-se.

Observamos que tanto o discurso da revista Activa como da Happy Woman têm geralmente um tom otimista que estimula a leitora a estar na sua melhor forma física, a realçar a sua beleza ou a melhorá-la cosmeticamente. Os conteúdos centram-se nas relações pessoais e sexuais que sublinham a «ambição feminina e o seu apetite erótico, além de fornecerem imagens sexualizadas de modelos femininos que, embora sejam apenas um pouco mais discretas do que as destinadas aos homens, têm a finalidade de simbolizar a emancipação sexual da mulher.» (WOLF, 1991:77)

\section{Conclusões}

O objetivo desta reflexão não é a crítica negativa à mitificação da sexualidade e da beleza da mulher projetada pelas revistas femininas portuguesas, mas sim alertar para o facto de que esta não deveria ser a representação feminina dominante. O universo feminino é tão vasto como o masculino, existem mulheres trabalhadoras, políticas, empresárias, profissionais, mulheres donas de casa, mulheres jardineiras... existe um sem fim de possibilidades de estereótipos e modelos que poderiam ser utilizados pelas revistas femininas. Porquê encontrámos nas edições da revista Activa e da Happy Woman uma maioria esmagadora de conteúdos editoriais dedicados às coisas supérfluas da vida quotidiana: beleza, maquilhagem, moda, acessórios? Seria de esperar que as jornalistas e editoras das revistas tivessem um maior respeito pela sensibilidade 
das leitoras e tentassem uma representação mais justa e real do mundo feminino: ou acaso o $70 \%$ das mulheres só pensa em questões relacionadas com a beleza? A explicação é simples, também essas mulheresjornalistas e editoras estão sob o jugo do discurso dominante da publicidade. Hoje em dia não é o preço da capa da revista que faz sobreviver as editoras e as revistas, são os anunciantes. E longe vai o tempo em que havia uma divisão clara e inequívoca entre $o$ departamento editorial e publicitário.

Nas revistas femininas encontramos uma dualidade antagónica do discurso: por um lado encontramos artigos pró-feministas e por outro, conteúdos que celebram o ideal de beleza perfeita, o mundo da cosmética, das cirurgias, da mulher-boneca, mulheradorno. Esta fórmula é patrocinada pelos anunciantes das revistas que controlam de forma quase direta os conteúdos, as opiniões, os ângulos das reportagens.

Na revista Activa encontramos uma preocupação de introduzir assuntos de foro internacional e da atualidade protagonizados por mulheres, visando um caráter informativo e de exaltação de mulheres que se destacaram na sua carreira.

Analisando os artigos de beleza e saúde, concluímos que a saúde é secundarizada em relação à magreza e à aparência e a elevada preocupação com o envelhecimento. Tanto a revista Activa com a Happy Woman aderem à cultura do corpo promovendo o ideal de beleza convencional, pelo que assistimos a uma tentativa de repressão e de regulação do corpo das mulheres, que permanece uma prática ainda nos dias de hoje e que as revistas ajudam a legitimar e a perpetuar.

As narrativas das revistas femininos não existem simplesmente para entreter as mulheres, mas sim para suportar os enormes impérios de produção que exercem a sua força através da publicidade, o financiamento direto ou indireto das empresas mediáticas e dos seus conteúdos. Uma cultura que pressiona os conteúdos a centrarem-se nas frustrações das leitoras, nas suas inseguranças, nas suas imperfeições frente ao espelho, em detrimento de uma efetiva e real cobertura do vasto mundo feminino.

$\mathrm{Na}$ revista Happy Woman existe a total ausência de artigos relacionados com a política, economia ou questões sociais. Transmite a ideia que a mulher ocupa um espaço público apenas na sua dimensão lúdica e de entretenimento, não tendo qualquer papel de intervenção ou poder.

Segundo Angela McRobbie (apud Silveirinha, 2001) dissertando sobre a revista inglesa Glamour, as revistas têm mudado, afastando-se de um tipo de sensibilidade doce, substituindo-se com uma subjetividade feminina muito mais assertiva e que procura o divertimento, o desaparecimento do romance e a construção da narrativa dominante sobre a sexualidade feminina. A linha editorial de Happy Woman enquadra nesta ideia proposta por McRobbie, com a promoção de novas sexualidades e ao mesmo tempo de um novo modelo de feminismo. Como diria Matheson (2005), o poder das revistas é claramente promover discursos que definem estilos de vida e especialmente discursos sexualizantes que definem quem somos. O incentivo ao consumo faz parte também da agenda da revista Woman, de uma forma mais agressiva que na revista Activa.

A nossa conclusão? Este género mediático emancipa a mulher e moderniza o mundo feminino, mas ao mesmo tempo reduz a mulher a um significado redutor onde a beleza continua a ser um colete-de-forças e a sexualidade o grande mito da felicidade.

\section{Referencias}

- ADORNO, Theodor W, «Indústria cultural e sociedade.», seleção de textos Jorge Mattos Brito de Almeida traduzido por Juba Elisabeth Levy... [et a1.]. — São Paulo, Paz e Terra, 2002

- BARTHES, R. «Mitologias» Lisboa: Edições 70,1988

- BETTERTON, R. «How do Women Look? The female nude in the work of Suzanne Valadon» Feminist Review, 19, Março, 1985
- FERIN, I. «Análise dos Media» Coimbra: Imprensa da Universidade de Coimbra, 2012

- FERREIRA, V. «Pensar» Venda Nova: Bertrand, 1992

- Fairclough, N. «Discurso e Mudança Social.» Trad. Izabel Magalhães. Brasília: UNB, 2001

- FOUCAUlt, M, «História da Sexualidade. O uso dos prazeres.» Rio de Janeiro. Ed Graal, 1984. (volume 1) 

Loyola; 10. ed., 2004.

. «A arqueologia do saber» Rio de Janeiro: Forense Universitária, 2007.

- FULTON, H. et alii. «Narrative and Media» Cambridge: Cambridge University Press. Cap.18. pp.271-284, 2005

- GAUNTLETT, D. «Media, Gender and Identity: An Introduction» London: Routledge, 2002.

- HALL, S. «Quem precisa de identidade?»In: SILVA, Tomaz Tadeu (Org.) Identidade e diferença: a perspectiva dos Estudos Culturais. Petrópolis: Vozes, 2000. p. 109.

- _. «A questão da identidade cultural» Tradução: Andréa B. M. Jacinto e Simone M.Frangella. 3. ed. ver. Campinas: IFCH/UNICAMP, 2005.

- HEYES, C J «A Foucauldian feminist reading: Cosmetic Surgery and the Televisual Makeover, Feminist Media Studies», 2007. p.17/32

- KRESS, G,; VAN LEEUWEN, T. «Front Pages: (the critical) analysis of newspaper layout», in Allan Bell and Peter Garret «Approaches to Media discourses». Oxford, Blackwell Publishers, 1998 pp.186-219

- LÉVI-STRAUSS, C. «The structural study of myth" in Structural Anthropology, Harmondsworth: Penguin, 1977 p .207

- LiPOVETSKY, G. «A Terceira Mulher - Permanência e Revolução no Feminino» São Paulo: Companhia das Letras, 2000

- MATHESON, D. «Media Discourses Analysing Media Texts,» Open University Press 2005, pag. 62

- MOTA-RIBEIRO, S. «Retratos de Mulher: construções sociais e representações visuais do feminino.» Campo das Letras. 2005
- MOTA-RIBEIRO, S.; PINTO-COELHO, Z. «Imagens de mulheres na imprensa portuguesa.» in Actas do IV Congresso da SOPCOM, «Repensar os Media: Novos Contextos da Comunicação e da Informação» 2005

- QuivY, R.; VAN CAMPENHOUDT, L.«Manual de Investigação em Ciências Sociais», Lisboa: Gradiva 1992

- Silveirinha, M. J. «O Discurso Feminista e o Discurso dos Media», 2001

. «As Mulheres e os Media.» Lisboa: Livros Horizonte. 2004

. «A Representação das Mulheres nos Media. Dos Estereótipos e Imagens de Mulher ao Feminino» In: Circuito da Cultura”, in J. P. Esteves (ed.), Comunicação e Identidades Sociais: diferença e reconhecimento em sociedades complexas e culturas pluralistas, Lisboa: Livros Horizonte, 2008

- SILVERMAN, D. «Research and Social Theory» In: Seale, C. Researching Society and Culture, London: Sage , 2004

- WOLF, Naomi. «O Mito da Beleza» Tradução de Octávio Gameiro. Lisboa: Difusão Cultural, 1991

\section{WEBSITES CONSULTADOS}

- http://www.Activa.pt

- http://www.marktest.com/wap/

- http://www.apct.pt

\section{CORPUS DE ANÁLISE}

- Revista Activa ( 12 edições de 2012) direção de Clara Marques, Abril / Controljornal, Editora Lda, Lisboa.

- Revista Happy Woman (12 edições de 2012) direção de Carla Ramos, Baleska Press, Lis-boa.

\section{Forma de Citación}

WICHELS, Susana: A MITIFICAÇÃO DA SEXUALIDADE NOS MÉDIA. Análise de Activa e Happy Woman. Revista Communication Papers, $N^{\circ}$ 2, páginas 41 a 53. Departamento de Filología y Comunicación de la Universidad de Girona. Recuperado el _ de_ de 2 de: http://www.communicationpapers.es 